\title{
Gene editing and RNAi approaches for COVID-19 diagnostics and therapeutics
}

\author{
Burak Berber $\mathbb{1}^{1} \cdot$ - Cihan Aydin $\mathbb{1}^{2} \cdot$ Fatih Kocabas $^{3}$ - Gulen Guney-Esken ${ }^{3} \cdot$ Kaan Yilancioglu ${ }^{4,5}$. \\ Medine Karadag-Alpaslan $\mathbb{1}^{6} \cdot$ Mehmet Caliseki $\mathbb{D}^{7} \cdot$ Melek Yuce $^{8} \cdot$ Sevda Demir $\mathbb{D}^{3} \cdot$ Cihan Tastan $\mathbb{D}^{5,9,10}$
}

Received: 3 May 2020 / Revised: 20 October 2020 / Accepted: 27 October 2020 / Published online: 14 December 2020

(C) The Author(s), under exclusive licence to Springer Nature Limited 2020

\begin{abstract}
The novel coronavirus pneumonia (COVID-19) is a highly infectious acute respiratory disease caused by Severe Acute Respiratory Syndrome-Related Coronavirus (SARS-CoV-2) (Prec Clin Med 2020;3:9-13, Lancet 2020;395:497-506, N. Engl J Med 2020a;382:1199-207, Nature 2020;579:270-3). SARS-CoV-2 surveillance is essential to controlling widespread transmission. However, there are several challenges associated with the diagnostic of the COVID-19 during the current outbreak (Liu and Li (2019), Nature 2020;579:265-9, N. Engl J Med 2020;382:727-33). Firstly, the high number of cases overwhelms diagnostic test capacity and proposes the need for a rapid solution for sample processing (Science 2018;360:444-8). Secondly, SARS-CoV-2 is closely related to other important coronavirus species and subspecies, so detection assays can give false-positive results if they are not efficiently specific to SARS-CoV-2. Thirdly, patients with suspected SARS-CoV-2 infection sometimes have a different respiratory viral infection or co-infections with SARS-CoV-2 and other respiratory viruses (MedRxiv 2020a;1-18). Confirmation of the COVID-19 is performed mainly by virus isolation followed by RT-PCR and sequencing (N. Engl J Med 2020;382:727-33, MedRxiv 2020a, Turkish J Biol 2020;44:192-202). The emergence and outbreak of the novel coronavirus highlighted the urgent need for new therapeutic technologies that are fast, precise, stable, easy to manufacture, and target-specific for surveillance and treatment. Molecular biology tools that include gene-editing approaches such as CRISPR-Cas12/13-based SHERLOCK, DETECTR, CARVER and PAC-MAN, antisense oligonucleotides, antisense peptide nucleic acids, ribozymes, aptamers, and RNAi silencing approaches produced with cutting-edge scientific advances compared to conventional diagnostic or treatment methods could be vital in COVID-19 and other future outbreaks. Thus, in this review, we will discuss potent the molecular biology approaches that can revolutionize diagnostic of viral infections and therapies to fight COVID-19 in a highly specific, stable, and efficient way.
\end{abstract}

\section{Highlights}

- SARS-CoV-2 is an RNA virus that could be targeted and diagnosed with novel CRISPR approaches.

- ASO therapy targeting transcript encoding a viral protein or genomic RNA itself could be developed as a response to the SARS-CoV-2 pandemic.

Cihan Tastan

cihantastan.ct@gmail.com

1 Department of Biology, Faculty of Science, Eskisehir Technical University, Eskisehir, Turkey

2 Department of Molecular Biology and Genetics, Faculty of Engineering and Natural Sciences, Istanbul Medeniyet University, Istanbul, Turkey

3 Department of Genetics and Bioengineering, Faculty of Engineering, Yeditepe University, Istanbul, Turkey

4 Institute of Addiction and Forensic Sciences, Uskudar University, Istanbul, Turkey

5 Transgenic Cell Technologies and Epigenetics Application and Research Center (TRGENMER), Uskudar University, Istanbul, Turkey
6 Department of Medical Genetics, Faculty of Medicine, Ondokuz Mayis University, Samsun, Turkey

7 Department of Molecular Biology, Genetics and Bioengineering, Graduate School of Engineering and Natural Sciences, Sabanci University, Istanbul, Turkey

8 Center for Stem Cell Research, Ondokuz Mayis University, Samsun, Turkey

9 Acibadem Labcell Cellular Therapy Laboratory, Istanbul, Turkey

10 Faculty of Science and Letters, Department of Molecular Biology and Genetics, Istanbul Kultur University, Istanbul, Turkey 
- Antisense peptide nucleic acids, which have significant potential as antiviral agents, are important therapeutic candidates that can target SARS-CoV-2 RNA with high hybridization affinity and stability.

- Although ribozyme and aptamer technologies are relatively older than other gene-editing technologies, they are still strong candidates in the fight against the COVID-19 pandemic due to their high specificities and low toxicities, besides that aptamers are highly reproducible.

- siRNAs that target structural or non-structural proteins of SARS-CoV-2, could inhibit assembly and replication of SARSCoV-2.

\section{Introduction to the basic structure of SARS- CoV-2 to understand the potential targets for the novel diagnostic and therapeutic approaches}

Coronaviruses have a high prevalence and wide distribution around the world. It has a wide genetic diversity due to its RNA-based genomes with a high mutation rate. This is likely, given the recurrent [1-11] outbreaks, that new coronaviruses will appear periodically in humans $[12,13]$. The last coronavirus pandemic, which was named later as Coronavirus Disease 2019 (COVID-19), is caused by the Severe Acute Respiratory Syndrome Coronavirus 2, namely SARS-CoV-2 [14]. SARS-CoV-2 has a 29,903 base of single and positive-strand RNA genome (SARS-CoV-2 Wuhan Hu-1 strain. Accession: NC_045512) encoding several structural and non-structural proteins (nsps) $[15,16]$. Although SARS-CoV, MERS-CoV, and SARSCoV-2 can cause severe disease, HKU1, NL63, OC43, and 229E are associated with mild symptoms [17]. The SARSCoV-2 has a non-segmented RNA genome, which encodes four major structural proteins on the virions: the nucleocapsid $(\mathrm{N})$ protein, the transmembrane $(\mathrm{M})$ protein, the envelope (E) protein, and the spike (S) protein [18-20]. While the $\mathrm{N}$ protein takes part in the replication of viral RNA and the host's cellular response to viral infection [21]. The $\mathrm{S}$ glycoprotein is a type 1 membrane glycoprotein with different functional domains including the amino (S1) and carboxy (S2) termini. While the S2 subunit is a transmembrane protein mediating the fusion of viral and cellular membranes, the S1 subunit is associated with receptor binding functions $[21,22]$ the $\mathrm{M}$ protein of SARS-CoV-2 plays a central role in virus assembly by turning virus and host factors to make new virions on cellular membranes [23]. While the E protein is localized at the ER, Golgi, and ER-Golgi intermediate compartment, which is associated with assembly and budding of SARS-CoV-2 in the site of intracellular trafficking [18]. The nsps and structural proteins that are pivots of the pathophysiology and virulence mechanisms of SARS-CoV-2 are potential targets for the novel molecular biology toolbox including CRISPR-Cas, antisense oligonucleotides (ASO), peptide nucleic acids
(PNAs), ribozymes, and siRNA. In this review, we will discuss potent molecular biology approaches that can be used in the diagnostic of SARS-CoV-2 and therapies against the COVID-19 infection in a highly specific, stable, and efficient way.

\section{CRISPR-Cas diagnosis and therapeutic tools for SARS-CoV-2 infection}

CRISPR (Clustered Regularly Interspaced Short Palindromic Repeats)-Cas (CRISPR-associated) systems have improved our ability to edit genes and modulate gene expression. The mechanism naturally defends bacteria against invading bacteriophages and other foreign nucleic acids [24]. DNA-targeting effectors like Cas9 ensure protection against DNA bacteriophages, and RNA-targeting activity for type III and VI effectors provide defense against RNA pathogens. This suggests that CRISPR effectors could be reprogrammed to aid mammalian cells defending against both DNA and RNA viruses. Indeed, recent Cas9 applications have demonstrated that CRISPR effectors can suppress replication of double-stranded DNA viruses or singlestranded RNA (ssRNA) viruses with DNA intermediates in mammalian cells [24-31]. Also, many ssRNA viruses are human pathogens and lack US Food and Drug Administration (FDA)-approved therapies [32] that emphasize the need for new antiviral strategies. Recently characterized RNAand DNA-targeting Cas9 orthologs are less likely to be able to solve these needs, as they have low RNA-cleavage efficacy and could stimulate off-target effects on cellular DNA [27, 33]. CRISPR systems are extremely diverse in terms of the diversity of Protospacer Adjacent Motif (PAM) and the number and type of Cas proteins. CRISPR-Cas mechanisms with the CRISPR region and the content of the Cas genes are classified into three main types (I, II, and III) and 11 subtypes (I-A to I-F, II-A to II-C, and III-A to III-B) [34]. Type II gadget is the most studied machine and the mechanism is the best-illuminated device among those systems. The basic mechanism of the CRISPR-Cas9 system begins with the access of a overseas virus or plasmid DNA into the mammalian cell. Foreign nucleotides are identified with the aid of 
Cas complicated and are separated into $\sim 30$ base pairs in length and these fragments are inserted into the CRISPR sequence. This sequence consists of small fragments of overseas virus or plasmid DNA that it has previously encountered. Foreign oligo DNA with the PAM sequence may be inserted into the guide RNA centered web site with repetitive genes. Cas proteins specific and technique the CRISPR vicinity to produce CRISPR RNAs (crRNAs). In the Type II system, non-coding RNA transactivating crRNA acts as a skeleton that binds crRNA with Cas9 and helps the conversion of precursor crRNAs made from CRISPR sequences into mature crRNAs. Using collection homology, those crRNAs direct a Cas nuclease to the diagnosed exogenous genetic fabric facet subsequent to the species PAM and breaks the targeted DNA region into fragments to form insertion-deletion mutation [35-38]. It became hypothesized that this hobby can also be part of a programmed cell demise pathway in bacteria, allowing cells to commit cell suicide or end up dormant unless they get over infection. Fortunately, the collateral activity is undetectable in mammalian cells and flora making an allowance for many RNAtargeting programs to be developed the usage of Cas 13 . Many programs have additionally been built the use of Cas13s in mammalian cells, along with transcript knockdown, live-cellular transcript imaging [39] and RNA base editing [40]. While Cas13a confirmed some interest for RNA knockdown, certain orthologs of Cas13b proved greater stable and strong in mammalian cells for RNA knockdown and editing. More recently, additional orthologs of Cas13 have been discovered, along with Cas13d, which has been leveraged for green and strong knockdown across many endogenous transcripts [41]. Konermann et al. moreover confirmed that Cas13d may be used to modulate splicing of endogenous transcripts and that the coding collection for Cas $13 \mathrm{~d}$ is small enough to fit in the packaging limits of AAV for in vivo delivery [41]. RNA-targeting CRISPR effectors could offer a future promising possible antiviral approach. Recent studies about class 2 type VI CRISPR effector Cas 13 have highlighted its ability to efficiently target and cleave RNA in several model systems, including mammalian cells [39-46]. Moreover, Cas 13 can process its CRISPR array and let out individual crRNA [47], allowing for multiplexed targeting applications. Besides CRISPR array processing activity, Cas 13 has collateral cleavage activity that has been utilized for diagnostic applications, as specific high-sensitivity enzymatic reporter unlocking (SHERLOCK) approach [8, 48, 49]. Moreover, various Cas13 orthologues have minimal off-target effects on the host transcriptome as determined in several recent studies in mammalian cells [39-42]. This suggests that Cas 13 could be programmed to target and destroy a wide variety of mammalian viruses and could be useful as a novel antiviral platform.

\section{Recent advances in CRISPR diagnostic toolbox}

Although CRISPR gained popularity as a genome-editing tool, its diagnostic potential was also noticed by researchers. In the past few years, CRISPR functionality has emerged as a location finder, rather than a site-specific cleavage tool. Cas12a (DNA-specific) and Cas13 (works with RNA) are particularly two popular nucleases in CRISPR diagnostics. A part of the mechanism resembles that of Cas9-a guide RNA that is complementary to the target sequence is required for specific binding and the $\mathrm{Cas} 12 \mathrm{a} / \mathrm{Cas} 13 \mathrm{a}$ nuclease cleaves at the site. An amazing feature of Cas 12 and Cas 13 nucleases is that they show trans or collateral cutting activity. After finding the target, the nucleases will cut other non-targeted nucleic acid molecules in the close area as well. This property is leveraged to create reporter systems for a visual readout in CRISPR diagnostics.

\section{CRISPR-Cas13 diagnostic}

In 2017, the first reported CRISPR-based nucleic acid detection technique called SHERLOCK was announced by Feng Zhang's group [50]. This technique allows multiplexed, portable, and ultra-sensitive detection of RNA or DNA from clinically relevant samples. SHERLOCK analyses recombinase-mediated polymerase pre-amplification of DNA or RNA and subsequent Cas13- or Cas12-mediated detection via fluorescence and colorimetric readouts that provide results in less than $1 \mathrm{~h}$ with a setup time of $<15 \mathrm{~min}$. SHERLOCK analyses recombinase-mediated polymerase pre-amplification of DNA or RNA and subsequent Cas13- or Cas12-mediated detection via fluorescence and colorimetric readouts that provide results in less than $1 \mathrm{~h}$ with a setup time of $<15 \mathrm{~min}$. Open-access SHERLOCK research protocols and design resources for SARS-CoV-2 are using CRISPRCas13. The Cas13 enzymes are classified as programmable RNA-guided Type VI CRISPR enzymes with nuclease activity. The Cas13 enzymes can target and knockdown the gene without editing the genome, which makes it a potential therapeutic for interfering gene expression without permanently altering the genome sequence.

The recent coronavirus (COVID-19) outbreak presents enormous difficulties for global health. Zhang et al. has developed a research protocol along with the CRISPRCas13 based diagnostics for SARS-CoV-2 [51]. Similarly, Metsky et al. has developed an assay design tool and a research method for detecting specifically SARS-CoV-2 and 66 related viruses, as described in a bioRxiv preprint [51].

The described research techniques provide the basic framework to set up SHERLOCK-based COVID-19 tests 
by using paper strips. SHERLOCK system is based on the CRISPR-Cas13 and can detect specifically different RNA viruses in patient specimens. The system searches for unique nucleic acid sequences and uses a test strip resembling a pregnancy test to provide a visual readout. In a simple paper strip test along with a prepared sample, a line appears on the strip to determine whether the virus is present or not. To this end, they have designed and analyzed two RNA guides that recognize two signatures of COVID-19 by using synthetic SARS-CoV-2 RNA fragments. Thanks to the CRISPR-Cas13 riboprotein complex that forms the SHERLOCK system, it is accomplished to detect the presence of SARS-CoV-2 viral RNA in a COVID-19 patient specimen [8, 50, 52]. The RNA samples extracted for current qPCR tests can be used. In their recent method, Zhang et al. [52] targeted two genes, $\mathrm{S}$ gene and Orflab, specific to the COVID-19 genome along with synthetic COVID-19 virus RNA fragments as positivecontrol tests [52].

The SHERLOCK COVID-19 virus detection method involves two major steps:

(1) The synthetic viral RNA amplification is using recombinase polymerase amplification (RPA) technology that is followed by in vitro amplified DNA transcription back into RNA,

(2) Cas13 RNA-detection and crRNA targeting specific sequences. Visual color readout using a commercially available paper dipstick captures which cleaved reporter RNA with labeled ends on specific antibody bands. The study showed that SHERLOCK could detect coronavirus target RNA sequences with a sensitivity of 10-100 copies/ $\mu$ l of patient specimen [52]. This suggests that RNA purified from patient nasal samples could be analyzed for the presence of COVID-19 in less than $1 \mathrm{~h}$ without special instrumentation.

Sabeti et al. developed a web-based platform that allows designing CRISPR-Cas13-based assay to identify 67 viruses, including SARS-CoV-2 and related respiratory viruses, where users can pick single or multiplex panels [51]. Each of these designs to be (1) comprehensive across genomic diversity by accounting for a large fraction of known sequence diversity ( $>97$ percent mostly), (2) predicted by a machine learning model to have large detection activity towards all targeted genomic diversity, and (3) estimated to have high target precision so that they can be grouped into panels that are targeted [51].

The researchers have also posted a bioRxiv preprint detailing these tools, focusing on a SHERLOCK SARSCoV-2 [51]. They checked the test on synthetic RNA fragments using both fluorescent and visual readout, with a sensitivity of 10 copies per microliter. The provided protocol can easily be adapted to the other 66 viruses [51].

In 2018, Mammoth Biosciences announced a new tool called DNA endonuclease-targeted CRISPR trans reporter (DETECTR) for the detection of DNA using Cas12a [53]. CRISPR-Cas12a (Cpf1) proteins are RNA-guided enzymes that bind and break DNA as bacterial-adaptive immune system components. Like CRISPR-Cas9, based on its ability to produce guided, double-stranded DNA breaks, Cas $12 \mathrm{a}$ is used for gene editing [53]. It is reported that RNA-guided binding of DNA unleashes indiscriminate cleavage operation of single-stranded DNA (ssDNA) by Cas12a, which fully degrades ssDNA molecules. Besides, target-activated, non-specific single-stranded cleavage deoxyribonuclease (ssDNase) is a feature of other CRISPRCas 12 type $\mathrm{V}$ enzymes [53]. Cas12a ssDNase activation along with isothermal amplification DETECTR method can detect target DNA at a very low concentration [51, 53]. DETECTR allows rapid and accurate identification in patient samples of human papillomavirus, thereby providing a novel platform for molecular diagnosis [53].

The Mammoth Biosciences team tested the identification of two genes, N-gene and E-gene, from the SARS-CoV-2 genome from engineered samples, based on CRISPR [51].

The following steps were included in their protocol:

(1) Amplification of the RNA extracted from samples using reverse transcription loop-mediated isothermal amplification.

(2) Detection of DNA using Cas12a and Synthegosupplied crRNA targeting specific sequences.

(3) Visual readout using commercially available dip strips as the same method with SHERLOCK.

In a comparison of the DETECTR (the sensitivity range is 70-300 copies/ $\mu$ input) to the SHERLOCK-based protocol (the sensitivity range is $10-100$ copies/ $\mu$ ), the DETECTR platform allowed faster detection (30 rather than $60 \mathrm{~min}$ ). This was largely due to the system that saved time spent on the additional IVT steps needed for Cas13a-based detection [51].

The DETECTR method could be further modified to identify SARS-CoV-2 RNA in as low as $30 \mathrm{~min}$. Such a rapid diagnostic method would be particularly useful in high-risk areas, such as airports and hospitals [51]. The Algorithm outputs are comprehensive across genomic diversity and are expected to be highly sensitive and accurate. SARS-CoV-2 prototypes were experimentally screened with a CRISPR-Cas13 detection system. Researchers have developed assay designs to identify 67 viral species and subspecies including SARS-CoV-2, phylogenetically-related viruses, and clinically specific viruses [51]. On the other hand, Mammoth Biosciences' 
DETECTR platform is still "slow" if compared to, for instance, Assay Genie's product which provides reliable results in $15 \mathrm{~min}$.

\section{CRISPR-Cas13 is adapted as an antiviral system against SARS-CoV-2}

Around two-thirds of the viruses that can infect humans, including deadly Ebola, Zika, and flu, have an ssRNA genome, and there is no FDA-approved treatment for any of these types of viruses. Vaccines have emerged as the prevailing solution to the war against infectious diseases but only 16 viruses have vaccines approved by the FDA [32]. A lot of new attempts have come out to develop antiviral drugs, such as small-molecule screening methods to classify viral and host target inhibitors. Identifying potent inhibitors of these targets also requires biological or mechanical understanding, which in the face of drug resistance or emerging pathogens may delay antiviral development [54]. Moreover, human viral pathogens are very complex and evolve rapidly, underlying both the developmental challenge and a great need for adaptable antiviral therapeutic platforms. The method harnesses the programmable RNAtargeting activity of Cas13 to build an end-to-end development platform called Cas13-assisted Viral Expression and Readout (CARVER), which combines Cas13-mediated viral RNA cleavage with a fast, Cas13-based diagnostic readout using the SHERLOCK platform [50, 54]. Scientists managed by a team at the Wide Institute of Massachusetts Institute of Technology and Harvard are now declaring the development of a CRISPR-Cas13 enzyme-based technology named CARVER (Cas13-aided viral expression and readout restriction), which can be programmed to kill RNAbased viruses in human cells [54]. The research is believed to be one of the first to harness Cas13, or any CRISPR device, as an antiviral in human cultured cells [54]. More recently, researchers have adapted Cas 13 which naturally targets viral RNA in bacteria as a method to cut and edit human RNA, and as a test to detect the existence of viruses, bacteria, or other targets. Researchers have studied the enzyme well in mammalian cells and can be guided to target different RNA sequences. Cas13 is fairly easy to deliver into cells. The CRISPR effector Cas13 may be an efficient antiviral for ssRNA viruses, because it complements its crRNA by programmable RNAs cleaves. The Cas 13 protein complexes with the guide RNA via the reputation of a short hairpin within the crRNA and target specificity is encoded by way of a 28-30-nt spacer that is complementary to the goal region. In hundreds of ssRNA viral species that can potentially infect humans, Freije et al. computationally described thousands of possible Cas 13 crRNA target sites [54]. Firstly, they explored Cas13's wide usefulness in targeting mammalian ssRNA viruses by computationally analyzing $>350$ viral genomes from species known or predicted to infect people [54]. The research experimentally tested the ability of Cas 13 to inhibit viral replication in three distinct ssRNA viruses: lymphocytic choriomeningitis virus (LCMV); influenza A virus (IAV); and VSV. Then, researchers conducted a genome-wide LCMV test and further optimized this antiviral approach by investigating the significance of Cas13 localization and multiplexing crRNAs and compared the success of Cas 13 and short hairpin RNAs (shRNAs) in establishing CARVER as a strong antiviral and diagnostic technology platform for a wide variety of ssRNA viruses [54].

\section{CRISPR-Cas13-based PAC-MAN approach to fight COVID-19}

PAC-MAN (prophylactic antiviral CRISPR in human cells), which is a CRISPR-Cas13-based technology can effectively degrade SARS-CoV-2 sequences and live IAV genome in human lung epithelial cells [55]. They designed and screened a group of crRNAs targeting conserved viral regions and diagnosed purposeful crRNAs for cleaving SARS-CoV-2. The study showed that the PAC-MAN approach can lower respiratory cellular viral replication for H1N1 IAV [55]. The bioinformatic evaluation also counseled a minimum pool of six crRNAs that can cover over $90 \%$ of sequenced coronaviruses. With the bioinformatics analysis performed in the study, it was also shown that the PAC-MAN system can target all sequenced coronaviruses with 22 crRNA pools. Thus, PAC-MAN can target different regions of a virus or different coronavirus strains simultaneously with the crRNA pool, preventing possible viral escapes and is a promising strategy to combat pancoronaviruses that will occur in pandemics [55]. They have also repurposed the RNA-guided RNA endonuclease activity of Cas $13 \mathrm{~d}$ in mammalian cells in opposition to emergent viral targets, SARS-CoV-2 and IAV, in the PACMAN strategy. This expands the packages of CRISPRCas13 systems in addition to their uses for diagnostics along with SHERLOCK and live-cellular imaging [48, 50, 54-56]. Prior work showed Cas13a/b systems may inhibit ssRNA viruses together with influenza, which is regular with our observed high performance of SARS-CoV-2 reporter and IAV inhibition the usage of the PAC-MAN approach [54]. PAC-MAN demonstrated that a Cas13d-based tool can successfully target and cleave the RNA sequences of SARSCoV-2 fragments and IAV in lung epithelial cell cultures. While this approach is a proof-of-concept and will require also testing the usage of replication-ready SARS-CoV-2 viruses and validation in animal models earlier than clinical checks in humans, it represents a unique method to 
implement a rapid and vast antiviral defense in human beings in opposition to rising pathogens for which there are no powerful vaccines. Traditional vaccines rely upon priming the immune system to viral proteins or peptides often derived from surface proteins that show off a high rate of mutation, which expands the chances of viral evasion of the host immune response [57]. In contrast, this has confirmed a genetic strategy that is able to target rather conserved regions, which could be predicted to make it much greater not likely for the virus to escape inhibition through mutation. Also, Cas13d can screen viral genome using a crRNA array way that multiple crRNAs concentrated on different areas could be delivered simultaneously [41], which may reduce the probabilities of viral escape.

\section{ASO as a COVID-19 therapeutic}

ASO technology targets mRNA, small RNA, or long noncoding RNA. ASO have chemically synthesized 15-50 nucleotides in length that are designed to bind RNA targets via complementary base pairing. ASO can act and modulate RNA function by two different mechanisms in the cells; (1) in the cytoplasm, ASO interferes with mRNA and prevent translation of the mRNA by the ribosome and block protein synthesis; (2) in the nucleus, ASO bind complementary sequence of an mRNA. The complementary base pairing between an ASO and mRNA leads to endonucleasemediated transcript knockdown as the RNA-DNA hybrid becomes a substrate for RNase $\mathrm{H}$. Transport of mRNA to the cytoplasm is blocked thus preventing protein production [58]. ASO therapy advantage is their application against any viral RNA of interest. ASO therapy is an emerging successful method used for myopathies, neurodegenerative diseases, oncology, and many other diseases [59-63] Clinical suitability of ASO drugs has been demonstrated in many human clinical trials [64-68]. Previous studies have demonstrated the efficacy of ASO in highly pathogenic viral infections by Ribovirus such as Ebola, influenza, HepatiteC, Japanese Encephalitis [69-72].

ASO technologies are also developed for the SARS-CoV to reduce the severity of infection, to treat and diagnose associated disease, and to detect the virus in human samples. Three patents using ASO for pathogenesis and virulence of SARS-CoV were published. Patent application WO2005023083 published by Ionis Pharmaceuticals describes the invention of an ASO that targets various regions of viral RNA to reduce the activity of the SARS virus, to prevent or treat and diagnose SARS virusassociated disease. In this study, hybrid DNA/RNA ASO was used for the disruption of the pseudoknot in the frameshift site of SARS-CoV [73]. AVI BioPharma, Inc. published a patent WO2005013905 relating the modified oligonucleotide compounds targeting $3^{\prime}$ terminal end of negative strand for treating ssRNA viral infection such as flavivirus, coronavirus, picornavirus, togavirus, calicivirus, and hepatitis E virus [74]. Another patent US20030224353 was published by Stein David described ASO ORF1, for SARS region $217-245 \mathrm{bp}$ antisense antiviral agent and method for treating ssRNA viral infection [75].

ASO could be directed against any genomic viral RNA of interest. Compared to viruses with a DNA genome, RNA viruses (other than retroviruses) are suitable to be targeted by ASO, so genomic RNA can be disturbed or completely degraded. However, viruses with DNA genome and retrovirus integrate stably host genome. In this case, mature mRNA transcript can be targeted by ASO and viral expansion can be disturbed. Thus, ASO therapy strategies to block SARS-CoV-2 virus infection can be designed to target the virus itself, by binding transcripts encoding a viral protein associated with replication and transcription. Barrey et al. designed recently ASO targeting viral RNA encoding protein associated with replication and transcription of SARS-CoV-2 to block the infection [76]. In this study, five candidates ASO were designed to target the genomic 5' UTR, ORF1a, and ORF1b expression of the replicase/ transcriptase complex, and the gene $\mathrm{N}$ encoding genomeassociated nucleoprotein. However, experimental validation should be done to demonstrate the effectiveness of each of these ASO [76].

Benjamin et al. demonstrated that ASO associated suppression of SARS-CoV replication can be achieved by targeting conserved RNA elements required for viral RNA synthesis and translation [77]. However, SARS-CoV escaped and developed resistance against ASO drug [77]. Beyond targeting viral proteins, using ASO against the viral RNA genome itself could be designed for the elimination of SARS-CoV-2. Although the viral genome has recently been sequenced, treatment with ASO is difficult because the conserved RNA sequences of SARS-CoV-2 are still unknown. Identifying conserved sequences is important to improve ASO targeting and to prevent viral escape.

The majority of oligo treatment utilizes systemic delivery intravenous or subcutaneous administration. Nevertheless, SARS-CoV-2 causes acute pulmonary injury and acute respiratory syndrome [78]. Delivering ASO drugs into the lung would be one of the greatest challenges for COVID-19 treatments. For SARS-CoV-2, a form of inhalation delivery to get the oligos directly into the airways and lungs is needed [79].

ASO therapies are produced for rare diseases. However due to their low toxicity effect, high specificity, and low cost of production to manufacture and easy to design, ASO therapy could be developed for SARS-CoV-2 pandemia [80]. 


\section{PNAs as antisense agents}

Antisense therapy is one of the important strategies developed for the treatment of malignant and viral diseases and is characterized by inhibiting gene translation of sequencespecific ASO that bind to target RNA [81]. PNAs, on the other hand, are an important oligonucleotide class which is defined as antigen and antisense therapeutic compounds. PNAs were first described in 1991 as a synthetic nucleobase oligomer in which the nucleic acid phosphodiester backbone was replaced by $\mathrm{N}$-(2-aminoethyl) glycine units via a methyl carbonyl binder [82]. These chemically stable synthetic nucleic acids are long-lasting in vivo and in vitro, since they are resistant against nuclease or proteases. These stable PNAs that have low or no binding affinity to serum proteins and having low toxicity even in relatively high concentrations are important candidates as antisense therapeutics or antigen technologies [83, 84].

Thanks to the flexible polyamide and uncharged backbone of PNAs, the geometry of bases, and high similarity of its structure with natural DNA and RNA molecules, they can easily hybridize with complementary DNA or RNA according to Watson-Crick base pairing [85]. They can bind to double-chain DNA in B-form, with single-stranded DNA or RNA in B-form which was discovered by James D. Watson and Francis Crick While PNAs can easily be designed for any target sequence, there are some limitations when trying to create triplex structures with doublestranded DNA. Due to the strong hybridization properties, stability, and low toxicity, PNA oligomers are important compounds for antisense and antigen applications. However, slow cellular uptake of PNAs appeared as a problem that has been tried to be overcome with various PNA modifications [85, 86] and recently nanotechnological approaches. For instance, PNAs coupled with gold nanoparticles (AuNPs) have become important candidates with their low toxicity, high biodistribution and biocompatibility, adjustable size and shape, and easy synthesis $[84,87]$.

\section{Use of PNAs as antisense agents}

The potential of PNAs to act as antisense agents was shown by Hanvey et al. in 1992 through a sequence and dose-dependent inhibition of transcription of DNA template expressing SV40 large T antigen with 15-mer PNA's nuclear microinjection [88]. They bind to RNA at 5' untranslated region and coding sequence and thus inhibit ribosome binding or translational elongation. In addition to these, they also act by binding to RNA regions that allow proteins to be transported from the nucleus to the cytoplasm [89].
The study examines the inhibition potential of HIV-1, MMLV, and AMV reverse transcriptases (RTs) of PNAs bound by triplex or duplex hybridization to target certain regions of the human immunodeficiency virus 1 (HIV-1) gag gene. It has been shown that all RTs have been stopped by the PNA/RNA complex when they are in sufficient concentration in the cell thus they act as an important reverse transcription inhibitor. Besides, since no sign of RNA degradation was observed, it was suggested that the effect of PNA was an only steric blockade, not RNase-H related [90].

PNAs can target more than one specific region such as dimerization initiation site to prevent genomic RNA packaging, att sequences of linear proviral DNA's U3 and U5 region to prevent the integration of viral genome with the host genome, and LTR region to inhibit strand transfer reaction during reverse transcription. Thus, it can block reverse transcription at many stages and show a more effective antiviral effect [91-93].

\section{PNA approaches for SARS-CoV-2}

In the treatment of COVID-19, approaches that can inhibit the viral life cycle at different stages will be important. In this direction, there are no clear studies on the use of PNAs, which are considered as suitable candidates. However, as mentioned in the previous section, PNA antisense therapeutic approaches have been developed for the treatment of retrovirus induced HIV. In a study, antisense PNAs were used against SARS-CoV which is genetically $79 \%$ similar to SARS-CoV-2 strains [94]. A SARS-CoV replicon expressing the luciferase reporter gene for cell-based analysis of antiviral activity was created and the -1 ribosomal frameshifting ( $-1 \mathrm{PRF})$ signal which controls the synthesis of viral RNA replicase polyproteins involved in virus genome replication was blocked by a fully compatible sequence-specific PNA. As a result, the intracellular amount of replicase proteins encoded by signal related ORF1b was reduced, replication of the SARS-CoV replicon was suppressed and an effective antisense strategy was achieved. The fact that the structure of the -1PRF signal was extremely stable and conserved turned this region into an important candidate for antiviral treatment. At the same time, it was found that the PNA which showed a difference of two bases with the target was less effective in -1 frameshifting inhibition when compared with fully compatible PNA (94\% efficiency at specific concentration) [95]. This result is an indication that PNA oligomers require more specificity when binding to DNAs or RNAs when compared to binding between DNA strands.

There are some important difficulties in the use of PNAs as antiviral therapy against the SARS-CoV-2 RNA 
genome. One of these is the fact that the conserved genome regions of SARS-CoV-2 are fully known yet [96]. However, one of the major problems known for PNAs is slow cellular uptake. Due to the negatively charged phosphate backbones, PNAs have been reported to tend to fold into complex globular structures when in solution, possibly due to intra and intermolecular affinity between their hydrophobic nucleobases. The hydrophobicity and tendency to an aggregate of PNAs impose various limitations. Hydrophobicity that supports PNA aggregation appears to promote relatively non-specific adhesion to both other macromolecules and larger surfaces [97]. Using liposomes as a model for cellular membranes, researchers have stated that PNAs are not readily absorbed by cells, although they are neutral. This indicates that PNAs are more lipophilic than oligonucleotide but are present in aqueous sections of liposomes rather than being dissolved in the lipid membrane [98].

Although nanotechnological tools such as gold nanoparticles and some modifications have been applied for the solution of this problem, no studies have been conducted for SARS-CoV-2 antiviral therapy. While there are studies on the transmission of siRNA to the lungs through means of transmission such as lipid nanoparticles [99], the applicability of this for PNAs, determination, and optimization of the effective dose is significant difficulties that should be overcome.

\section{Ribozymes and aptamers in the fight with SARS-CoV-2}

Scientific studies on the RNA molecule in the last 50 years have provided a better understanding of the complex structure of this molecule. Ribozymes are RNA molecules with catalytic function. This catalytic function is provided by binding and cleavage of the phosphodiester bonds in a target nucleic acid. In this way, protein synthesis from the target region is prevented. Ribozymes are classified according to their size and reaction mechanisms [100]. The specific inactivation of target RNAs by ribozymes suggests that they could be effective in treating viral diseases via their gene-editing activities. Indeed, ribozyme-based gene regulation studies have been carried out in diseases caused by RNA viruses including HCV, HIV, and influenza. Most of the gene-editing studies carried out by ribozymes had utilized easily modified small ribozymes such as the hammerhead, the hairpin, hepatitis delta, and the Varkud satellite (VS) ribozyme [101-106].

Some important issues should be taken into consideration while performing ribozyme-based antiviral therapy. For example; the target region should be conserved and vital for the virus, the target region should be accessible, and the ribozyme should be able to easily bind to the target region. Also, an effective delivery mechanism is an important factor that increases the robustness of therapy.

The major disadvantage of ribozymes is that their cleavage effects in vivo are not the same as in vitro. Moreover, unmodified ribozymes generate a short-term effect when they are administered alone in vivo [107-109]. The possible reason for this could be the interaction of the ribozyme in cellular traffic and its half-life. Yet, this does not mean that ribozyme technology is completely unsuccessful and unusable. On the contrary, improvements in this technology will further increase its functionality and success rate. Longterm in-vivo expression of ribozymes and permanent treatment of the disease could be possible by mediator molecules or chemical modifications. Some chemical modifications made in ribozyme molecules have prevented their degradation in the cell [110].

There have not been developed an effective, fast, permanent, and reliable treatment strategy for SARS and MERS infections. Because they come from the same family and their genetic structures are similar [111], many of the treatment strategies tried for SARS-CoV-2 have been inspired by those treatment methodologies. Since they are all RNA viruses and are very prone to new mutations that adversely affect the development of treatment strategies, it is also become more difficult to find a definitive treatment for SARS-CoV-2. However, in 2007, the DNA/RNA chimeric ribozyme that can be used in the treatment of the general coronavirus has been designed and also taken into patent protection by Japan scientists (JP2007043942). This chimeric ribozyme is a ribozyme that targets and cuts conserved regions in the coronavirus family and could be adapted to SARS-CoV-2 treatment strategies or studies, as well.

Lee et al. [112] have combined the ribozyme molecule as a gRNA with the CRISPR/Cas9 system and they have tested their effectiveness both in vitro and in zebrafish embryos [112]. It was reported that the combination of ribozyme and CRISPR/Cas9 technologies increased gene disruption in the target region. Besides, a similar study has been reported for the treatment of malaria, as well [113]. In short, using ribozyme technology, in conjunction with Cas9, or even Cpf1 nuclease could increase the effectiveness of the strategies [114]. Ribozyme therapy is an important therapy due to its features such as high specificity and lack of immunogenic response compared to some other therapies [115]. Therefore, the combination of ribozyme technology with antiviral drugs to treat SARS-CoV-2 infection could strengthen treatment efficacy as it was shown in HIV with other gene therapy technologies [116, 117].

Aptamers are a type of oligonucleotides that can be used in gene therapy and treatments of viral diseases. They are 
small and single-chain oligonucleotides that bind to the target molecule with high affinity. They have been preferred in various studies because of their significant advantages such as high affinity, ease of chemical modification, lowcost, low-temperature sensitivity, rapid synthesis, and largescale production. RNA aptamers have been used to suppress viral infection in Human Papillomavirus Type 16, Avian Influenza Virus, and Hepatitis C virus (HCV) studies [118120]. However, the biggest disadvantage of aptamers is that they are unstable within the cell, but with some modifications, aptamers could become more stable. There are a plethora of chemical modifications leading to aptamers stabilization [121, 122].

Aptamers are combined with ribozymes to produce catalytic molecules called aptazyme. It has been reported that combining aptazymes with the CRISPR/Cas system as gRNA increases gene-editing efficiency [123]. In addition, aptamers that have been combined with siRNA technology to stop HIV-1 expression were also reported [124]. Two patent applications in Korea (KR2009128837 and KR2012139512) related to inhibition SARS virus were also reported [125]. Therefore, by using similar methods and inventions, aptamer technology could be a useful strategy for the treatment of SARS-CoV-2 infections.

Aptamer technology could be used not only in the treatment but also in the diagnosis of COVID-19 by binding to antigenic viral proteins. Aptamer Group is planning to use a combination of enzyme-linked oligonucleotide assay with aptamer technology for the diagnosis of COVID-19 in the near future [126, 127]). Moreover, an aptamer-based nanosensor developed by Pinpoint Science is expecting to rapidly diagnose COVID-19. There is also a detailed project proposal regarding the use of aptamers in the treatment of COVID-19 [128]. Finally, some studies in the SARS epidemic period have demonstrated that aptamer technology could work for the diagnosis of the COVID-19 [129, 130].

\section{RNAi based approaches for COVID-19 therapy}

RNA interference (RNAi) mechanism has been used for the silencing of genes that are related to cancer, viral infections, and autoimmune diseases. microRNAs, siRNAs, and shRNAs are the key molecules for the activation of RNAi mechanisms. siRNAs, short interfering RNAs, are noncoding dsRNA molecules that are 21-25 bp in length [9, 50, 131-133]. siRNAs, depending on homology and due to the presence of $2 \mathrm{nt} 3^{\prime}$ overhangs that are recognized by the PAZ domain of Dicer, are important for guiding the Dicer processing and the generating of the suitable guide strand. siRNAs bind to target mRNA depending on homology. Binding-complexes are recognized by RNAi mechanisms that cause degradation of the target mRNA or via RISC activation (RNA-induced silencing complex) translation can be inhibited [131, 132]. For siRNA mediated RNA interference, two different methods have been used for siRNA mediated RNA interference. One is the RNAbased strategy; synthetically produced siRNAs can be transferred to target cells using specific transporters. Another one is the intracellular production of siRNA via DNA-based strategies. In this method, plasmids that are encoding shRNA have been designed and used. In the nucleus, shRNAs are produced and cleaved by Drosha and DGCR8, transferred into the cytoplasm via exportin 5. By Dicer cleavage in the cytoplasm, shRNAs turn into siRNAs that trigger RNAi mechanism [132].

siRNAs can be used for the silencing of SARS-CoV-2 genes which encode structural and nsps. Genomes of SARS-CoV-2 encode four structural proteins, these are envelope (E), membrane (M), nucleocapsid $(\mathrm{N})$, and spike (S) proteins which are crucial for the assembly of the virion and inhibition of viral replication in humans. For the drug development, the genes encoding these viral structural proteins have been targeted with developing siRNAs [133]. siRNAs have been shown to suppress SARS-CoV gene expression [134]. Along with suppressing gene expression, it also inhibits virus replication. Different siRNA targeting studies have been analyzed by targeting SARS-CoV E, M, $\mathrm{N}$, and $\mathrm{S}$ genes. As a different approach, instead of targeting SARS-CoV genes by siRNA, the leader sequences of SARS-CoV genes were targeted. Leader sequences of S, E, $\mathrm{M}, \mathrm{N}$ genes were analyzed and common sequences for all four genes were targeted by a siRNA. Inhibition of virus replication was shown using siRNA in SARS-CoV-infected Vero E6 cells [135]. According to the approach and result in this study, targeting multiple genes with siRNA by finding common sequences from the leader sequences may be more effective in inhibiting virus replication. As a current approach to SARS-CoV-2 siRNA studies, researchers have identified potentially siRNAs that could target the SARS$\mathrm{CoV}-2$ virus. In this study, nine conserved siRNA regions that could target the SARS-CoV-2 genome (MN908947, https://www.ncbi.nlm.nih.gov/nuccore/MN908947)) were analyzed [136] (Table 1).

In a Chinese patent (CN101173275), two different siRNA was designed to silence the $M$ protein-encoding gene of SARS-CoV. siRNA-M1, one of siRNA, is complementary with M protein's mRNA sequence, 220-241 nucleotides and other siRNA is complementary with its 460-480 nucleotides. Using these two siRNAs, inhibition of $\mathrm{M}$ protein mRNA was shown, and interference efficiency of siRNAs was determined as over $\% 70$ [131, 137-139]. A patent application (US20050004063) includes six siRNAs 
Table 1 siRNAs that are characterized by SARS-CoV and potential siRNA targeting the SARS-CoV-2 genome.

\begin{tabular}{lll}
\hline Virus & Patent or article & Target region \\
\hline SARS-CoV & CN101173275 (1023405-01-7) (1023405-02-8) & 220-241 region of M protein \\
SARS-CoV & CN101173275 (1023405-03-9) (1023405-04-0) & 460-480 region of M protein \\
SARS-CoV & US20050004063(821121-38-4) & 1194-1213 bp of replicase A1 \\
SARS-CoV & CN1569233 (872062-82-3) & Nucleoprotein N \\
SARS-CoV & CN1569233 (872067-98-6) & Proteolytic enzyme \\
SARS-CoV-2 & {$[136]$} & Orf1ab $(6509-6531)$ \\
SARS-CoV-2 & {$[136]$} & Orf1ab $(7168-7188)$ \\
SARS-CoV-2 & {$[136]$} & Orf1ab $(11,997-12,017)$ \\
SARS-CoV-2 & {$[136]$} & Orf1ab $(12,001-12,021)$ \\
SARS-CoV-2 & {$[136]$} & Orf1ab $(15,041-15,064)$ \\
SARS-CoV-2 & {$[136]$} & S (22,391-22,411) \\
SARS-CoV-2 & {$[136]$} & Orf3a $(25,693-25,717)$ \\
SARS-CoV-2 & {$[136]$} & M $(27,128-27,148)$ \\
SARS-CoV-2 & {$[136]$} & N $(28,688-28,711)$ \\
\hline
\end{tabular}

(SARSi-1 to -6) which target mRNA sequences of replicase A1 gene region and experimental results showed that virus infection and replication was inhibited in FRhk-4 cells, especially with SARSi-4 (CAS RN821121-38-4) [133]. In the CN1569233 patent, designed siRNAs that targets nucleoprotein $\mathrm{N}$ and proteolytic enzyme, inhibit around \% 90-95 SARS-CoV in the BJo1 strain (Table 1).

SARS-CoV-2 also has 15 nsps Nsp1 to Nsp10 and Nsp12 to Nsp16 which are encoded by genes on ORF1ab and ORF1a. Nsp3, papain-like protease, is responsible for cleaving polyprotein 1a to make Nsp1, Nsp2, and Nsp3. Nsp5 (main, 3C-like protease) and Nsp12 (RNA-dependent RNA polymerase) regulate viral replication [133]. Nsp10/ Nsp16 (2'O-methyltransferases) and Nsp10/Nsp14 complexes facilitate methyltransferase activity. According to a study, separately expressed Nsp9 and Nsp10 cause the induction of IL-8 and IL-6 via targeted NKRF in lung epithelial A549 cells. By targeting Nsp9 and Nsp10 with siRNA, induction of IL-8/IL-6 can be reduced, thereby minimizing neutrophil-related lung damage [138]. Targeting nsps is also important for the inhibition of viral replication and the reduction of viral symptoms.

As a different approach, genes encoding human proteins associated with SARS-CoV-2 proteins are also targeted by the designed siRNAs. There is one proposal which is aiming to suppress the ACE2 gene for the treatment of SARSCoV-2 via siRNA mediated RNAi [140]. In this proposed strategy, virus infection will be prevented as the RBD region of the spike protein cannot bind to the ACE2 receptor [140]. This strategy was used for SARS-CoV and resulted as viral replication was reduced in Vera E6 cells [141]. Delivery strategies of siRNAs are planned using stable nucleic acid-lipid particles (SNALP liposome) or using an inactivated virus as siRNA carrier [140]. However, non-specific targets of siRNA might cause undesirable immunogenicity, and suppression of the ACE2 gene might cause different symptoms in humans. In another study for SARS-CoV and MERS-CoV treatment, siRNAs were designed to target ABL kinases (Abl1 and Abl2) which regulate several cellular processes. According to experimental results, knockdown of ABL2 by siRNA in Vero E6 cells causes considerable inhibition for replication SARSCoV and MERS-CoV [142].

For the treatment of COVID 19, an appropriate in vivo transport strategy should be chosen when in vitro analysis and characterization of siRNAs targeted to SARS-CoV-2 genes is complete. Naked siRNA molecules cannot effectively pass through the cell wall due to their large size and high negative charges density. Also, acute lung injury has been established because SARS-CoV and SARS-CoV-2 viruses infect lung type-2 epithelial cells [143]. For COVID-19, a respiratory disease, developed siRNAs could be given to patients via pulmonary route by inhalation, intratracheal aerosol delivery, intranasal delivery [99]. The intense mucus layer, alveolar macrophages, pulmonary proteases are a barrier for siRNAs to reach target cells due to inflammation caused by acute lung injury [99]. Pulmonary administered naked siRNAs degrade by macrophages and neutrophils, which are sensitive to foreign particles [99]. These restrictions can be mitigated for aerosol administration using the lipidic, polymeric, peptide, or inorganic origin siRNA nanocarrier systems and additionally anti-mucosal agents. Lipid-based nanoparticles (LNPs) can be used for the delivery of siRNAs. siRNAs are encapsulated by using LNPs which provide penetration ability to target tissue and more stability [144]. In addition, SNALPS, developed by Alnylam (Patisiran, siRNA-based drug) could be used for siRNAs delivery [144]. 
Fig. 1 This figure was created by compiling the data of many articles. In the figure, the activities indicated by a plus, relatively. One plus $(+)$ shows the lowest and three-plus $(+++)$ the highest activity. Gene editing and RNAi approach for COVID19 diagnostics and therapeutics are classified based on stability, specificity, delivery, ease of use, toxicity, and cost of production.

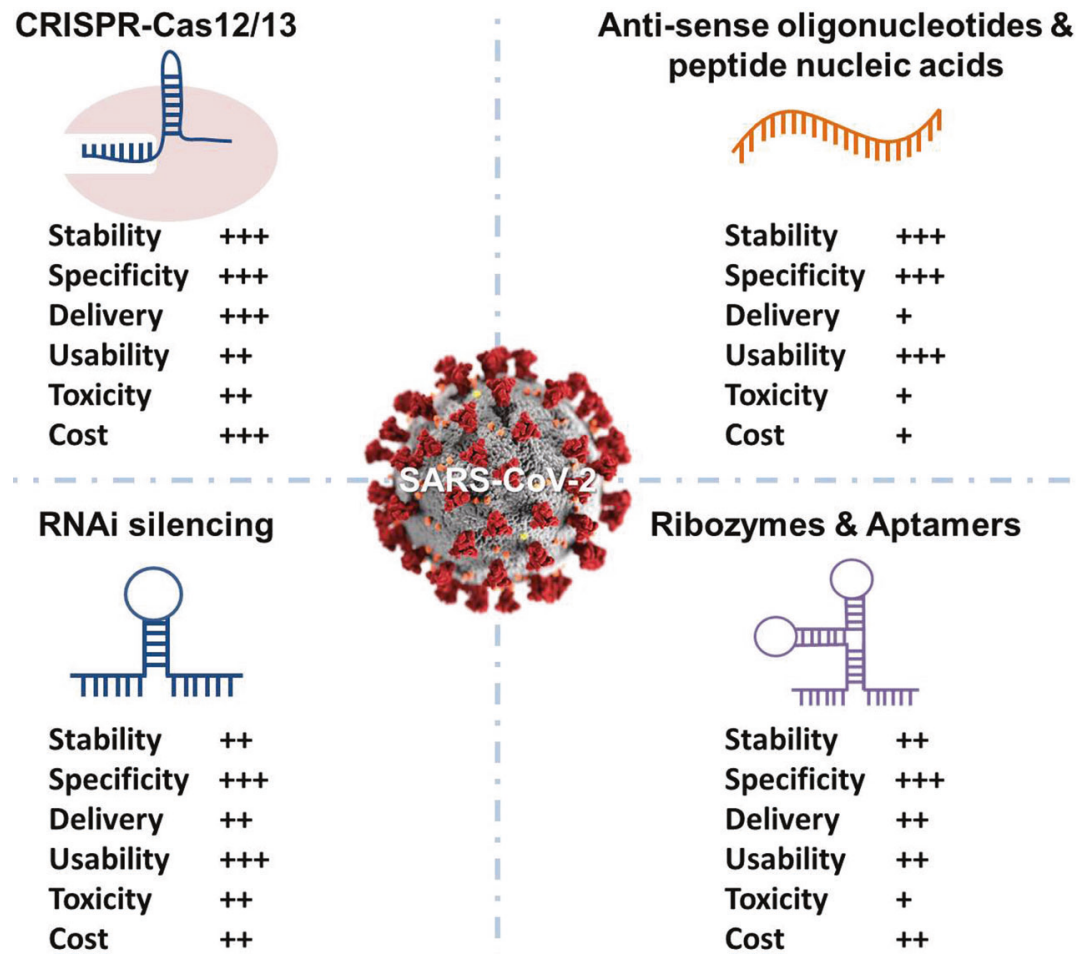

\section{Conclusion}

Coronavirus disease (COVID-19) is a particularly infectious respiratory disease caused by a newly discovered coronavirus, SARS-CoV-2. The emergence and outbreak of the novel coronavirus highlighted the urgent need for new therapeutic technologies that are fast, precise, stable, easy to manufacture, and target-specific for surveillance and treatment. Molecular biology tools that include gene-editing approaches such as CRISPR-Cas12/13-based SHERLOCK, DETECTR, CARVER and PAC-MAN, ASO, antisense peptide nucleic acids, ribozymes, aptamers, and RNAi silencing therapies produced with cutting-edge scientific advances compared to conventional diagnostic or treatment methods could be vital in COVID-19 and other future outbreaks. From a shorter and easier diagnosis to more targeted virus detection and killing, these tools can enter our lives as new generation diagnosis and treatment methods. Thus, in this review, we summarized the robust molecular biology toolbox that is studied for diagnosis of SARS-CoV2 and treatment against the viral infection, which can be alternative biotechnological drugs in the future to conventional vaccines and drugs.

Also, in this review, we have created a comparative graph by discussing the information obtained from studies conducted with these molecular biology tools that can be used in the future in the treatment of viral infections specific to SARS-CoV-2 (Fig. 1). In particular, we created a comparison idea between durability, specificity, handling, availability, toxicity, and cost of production (Fig. 1). Based on published studies, we think that CRISPR and ASO/ peptide nucleic acids are more resistant to purely RNAbased RNAi silencing and ribozyme/aptamers, although there are no such statistical comparative publications yet. Despite this, we anticipate that CRISPR systems may be more costly and perhaps toxic than all other systems (Fig. 1). However, we think that the cheapest method would be ASO or peptide nucleic acid. Comparative studies to be conducted in the future will give us a clearer idea about which or which of these systems will enter our lives more quickly, easily, effectively, and cheaply (Fig. 1).

\section{Compliance with ethical standards}

Conflict of interest The authors declare that they have no conflict of interest.

Publisher's note Springer Nature remains neutral with regard to jurisdictional claims in published maps and institutional affiliations.

\section{References}

1. Diao K, Han P, Pang T, Li Y, Yang Z. HRCT imaging features in representative imported cases of 2019 novel coronavirus pneumonia. Prec Clin Med. 2020;3:9-13. https://doi.org/10. 1093/pcmedi/pbaa004.

2. Huang C, Wang Y, Li X, Ren L, Zhao J, Hu Y, et al. Clinical features of patients infected with 2019 novel coronavirus in Wuhan, China. Lancet. 2020;395:497-506. https://doi.org/10. 1016/S0140-6736(20)30183-5. 
3. Li Q, Guan X, Wu P, Wang X, Zhou L, Tong Y, et al. Early transmission dynamics in Wuhan, China, of novel coronavirusinfected pneumonia. N. Engl J Med. 2020a;382:1199-207. https://doi.org/10.1056/NEJMoa2001316.

4. Zhou P, Yang X, Lou, Wang XG, Hu B, Zhang L, et al. A pneumonia outbreak associated with a new coronavirus of probable bat origin. Nature. 2020;579:270-3. https://doi.org/10. 1038/s41586-020-2012-7.

5. Wenzhong L, Hualan Li. COVID-19: Attacks the 1-Beta Chain of Hemoglobin and Captures the Porphyrin to Inhibit Human Heme Metabolism. ChemRxiv. 2019. https://doi.org/10.26434/ chemrxiv.11938173.v9.

6. Wu F, Zhao S, Yu B, Chen YM, Wang W, Song ZG, et al. A new coronavirus associated with human respiratory disease in China. Nature. 2020;579:265-9. https://doi.org/10.1038/s41586020-2008-3.

7. Zhu N, Zhang D, Wang W, Li X, Yang B, Song J, et al. A novel coronavirus from patients with pneumonia in China, 2019. N. Engl J Med. 2020;382:727-33. https://doi.org/10.1056/NEJMoa 2001017.

8. Myhrvold C, Freije CA, Gootenberg JS, Abudayyeh OO, Metsky HC, Durbin AF, et al. Field-deployable viral diagnostics using CRISPR-Cas13. Science. 2018;360:444-8. https://doi.org/10. 1126/science.aas8836.

9. Wang M, Wu Q, Xu W, Qiao B, Wang J, Zheng H, et al. Clinical diagnosis of 8274 samples with 2019-novel coronavirus in Wuhan. medRxiv. 2020. https://doi.org/10.1101/2020.02.12. 20022327. PPR:PPR112805.

10. Chen $\mathrm{C}$, Huang J, Cheng Z, Wu J, Chen S, Zhang Y, et al. Favipiravir versus arbidol for COVID-19: a randomized clinical trial. MedRxiv. 2020a. https://doi.org/10.1101/2020.03.17. 20037432

11. Taştan C, Yurtsever B, Sır Karakuş G, Dilek Kançağı D, Demir $\mathrm{S}$, Abanuz S, et al. SARS-CoV-2 isolation and propagation from Turkish COVID-19 patients. Turkish J Biol. 2020;44:192-202. https://doi.org/10.3906/biy-2004-113.

12. Wong G, Liu W, Liu Y, Zhou B, Bi Y, Gao GF. MERS, SARS, and Ebola: the role of super-spreaders in infectious disease. Cell Host Microbe. 2015. https://doi.org/10.1016/j.chom. 2015.09.013.

13. Cui J, Li F, Shi ZL. Origin and evolution of pathogenic coronaviruses. Nat Rev Microbiol. 2019. https://doi.org/10.1038/ s41579-018-0118-9.

14. Holshue ML, DeBolt C, Lindquist S, Lofy KH, Wiesman J, Bruce H, et al. First case of 2019 novel coronavirus in the United States. N. Engl J Med. 2020;382:929-36. https://doi.org/10. 1056/NEJMoa2001191.

15. Zhang L, Liu Y. Potential interventions for novel coronavirus in China: a systemic review. J Med Virol. 2020. https://doi.org/10. 1002/jmv.25707.

16. Zheng J. SARS-CoV-2: an emerging coronavirus that causes a global threat. Int J Biol Sci. 2020;16:1678-85. https://doi.org/10. 7150/ijbs. 45053 .

17. Andersen KG, Rambaut A, Lipkin WI, Holmes EC, Garry RF. The proximal origin of SARS-CoV-2. Nat Med. 2020;26:450-2. https://doi.org/10.1038/s41591-020-0820-9.

18. Schoeman D, Fielding BC. Coronavirus envelope protein: current knowledge. Virol J. 2019;16:69. https://doi.org/10.1186/ s12985-019-1182-0.

19. Hasöksüz M, Kiliç S, Saraç F. Coronaviruses and sars-cov-2. Turkish J Med Sci. 2020;50:549-56. https://doi.org/10.3906/sag2004-127.

20. Perlman S, Netland J. Coronaviruses post-SARS: update on replication and pathogenesis. Nat Rev Microbiol. 2009;7: 439-50. https://doi.org/10.1038/nrmicro2147.
21. Chen Y, Liu Q, Guo D. Emerging coronaviruses: genome structure, replication, and pathogenesis. J Med Virol. 2020c;92:418-23. https://doi.org/10.1002/jmv.25681.

22. Hasoksuz M, Sreevatsan S, Cho KO, Hoet AE, Saif LJ. Molecular analysis of the S1 subunit of the spike glycoprotein of respiratory and enteric bovine coronavirus isolates. Virus Res. 2002;84:101-9. https://doi.org/10.1016/s0168-1702(02) 00004-7.

23. Neuman BW, Kiss G, Kunding AH, Bhella D, Baksh MF, Connelly $\mathrm{S}$, et al. A structural analysis of $\mathrm{M}$ protein in coronavirus assembly and morphology. $\mathrm{J}$ Struct Biol. 2011;174:11-22. https://doi.org/10.1016/j.jsb.2010.11.021.

24. Wright AV, Nuñez JK, Doudna JA. Biology and applications of CRISPR systems: harnessing nature's toolbox for genome engineering. Cell. 2016. https://doi.org/10.1016/j.cell. 2015.12.035.

25. Liu X, Hao R, Chen S, Guo D, Chen, Y. Inhibition of hepatitis B virus by the CRISPR/Cas9 system via targeting the conserved regions of the viral genome. J Gen Virol. 2015. https://doi.org/ 10.1099/vir.0.000159.

26. Ophinni Y, Inoue M, Kotaki T, Kameoka M. CRISPR/ Cas9 system targeting regulatory genes of HIV-1 inhibits viral replication in infected T-cell cultures. Sci Rep. 2018. https://doi. org/10.1038/s41598-018-26190-1.

27. Price AA, Sampson TR, Ratner HK, Grakoui A, Weiss DS. Cas9-mediated targeting of viral RNA in eukaryotic cells. Proc Natl Acad Sci USA. 2015. https://doi.org/10.1073/pnas. 1422340112

28. Ramanan V, Shlomai A, Cox DBT, Schwartz RE, Michailidis E, Bhatta A, et al. CRISPR/Cas9 cleavage of viral DNA efficiently suppresses hepatitis B virus. Sci Rep. 2015. https://doi.org/10. 1038/srep10833.

29. Roehm PC, Shekarabi M, Wollebo HS, Bellizzi A, He L, Salkind $\mathrm{J}$, et al. Inhibition of HSV-1 replication by gene editing strategy. Sci Rep. 2016. https://doi.org/10.1038/srep23146.

30. Wang Z, Wang W, Cui YC, Pan Q, Zhu W, Gendron P, et al. HIV-1 employs multiple mechanisms to resist Cas9/Single guide RNA targeting the viral primer binding site. J Virol. 2018. https://doi.org/10.1128/jvi.01135-18.

31. Yin C, Zhang T, Qu X, Zhang Y, Putatunda R, Xiao X, et al. In vivo excision of HIV-1 provirus by saCas9 and multiplex singleguide RNAs in animal models. Mol Ther. 2017. https://doi.org/ 10.1016/j.ymthe.2017.03.012.

32. De Clercq E, Li G. Approved antiviral drugs over the past 50 years. Clin Microbiol Rev. 2016. https://doi.org/10.1128/CMR. 00102-15.

33. Strutt SC, Torrez RM, Kaya E, Negrete OA, Doudna JA. RNAdependent RNA targeting by CRISPR-Cas9. ELife. 2018. https:// doi.org/10.7554/eLife.32724.

34. Jiang F, Doudna JA. The structural biology of CRISPR-Cas systems. Curr Opin Struct Biol. 2015;30:100-11. https://doi.org/ 10.1016/j.sbi.2015.02.002.

35. Savić N, Schwank G. Advances in therapeutic CRISPR/Cas9 genome editing. Transl Res. 2016;168:15-21. https://doi.org/10. 1016/j.trsl.2015.09.008.

36. Doudna JA, Charpentier E. Genome editing. The new frontier of genome engineering with CRISPR-Cas9. Science. 2014;346: 1258096. https://doi.org/10.1126/science.1258096.

37. Ma Y, Zhang L, Huang X. Genome modification by CRISPR/ Cas9. FEBS J. 2014;281:5186-93. https://doi.org/10.1111/febs. 13110.

38. Nishimasu H, Ran FA, Hsu PD, Konermann S, Shehata SI, Dohmae N, et al. Crystal structure of Cas9 in complex with guide RNA and target DNA. Cell. 2014;156:935-49. https://doi.org/ 10.1016/j.cell.2014.02.001. 
39. Abudayyeh OO, Gootenberg JS, Essletzbichler P, Han S, Joung J, Belanto JJ, et al. RNA targeting with CRISPR-Cas13. Nature. 2017. https://doi.org/10.1038/nature24049.

40. Cox DBT, Gootenberg JS, Abudayyeh OO, Franklin B, Kellner MJ, Joung J, et al. RNA editing with CRISPR-Cas13. Science. 2017. https://doi.org/10.1126/science.aaq0180.

41. Konermann S, Lotfy P, Brideau NJ, Oki J, Shokhirev MN, Hsu PD. Transcriptome engineering with RNA-targeting type VI-D CRISPR effectors. Cell. 2018. https://doi.org/10.1016/j.cell. 2018.02.033.

42. Bawage SS, Tiwari PM, Santangelo PJ. Synthetic mRNA expressed Cas13a mitigates RNA virus infections. BioRxiv. 2018. https://doi.org/10.1101/370460.

43. Zhao X, Liu L, Lang J, Cheng K, Wang Y, Li X, et al. A CRISPR-Cas13a system for efficient and specific therapeutic targeting of mutant KRAS for pancreatic cancer treatment. Cancer Lett. 2018. https://doi.org/10.1016/j.canlet.2018.05.042.

44. Abudayyeh OO, Gootenberg JS, Franklin B, Koob J, Kellner MJ, Ladha A, et al. A cytosine deaminase for programmable singlebase RNA editing. Science. 2019. https://doi.org/10.1126/ science.aax7063.

45. Aman R, Ali Z, Butt H, Mahas A, Aljedaani F, Khan MZ, et al. RNA virus interference via CRISPR/Cas13a system in plants. Genome Biol. 2018a. https://doi.org/10.1186/s13059017-1381-1.

46. Aman R, Mahas A, Butt H, Ali Z, Aljedaani F, Mahfouz M. Engineering RNA virus interference via the CRISPR/Cas13 machinery in arabidopsis. Viruses. 2018b. https://doi.org/10. 3390/v10120732.

47. Shmakov S, Abudayyeh OO, Makarova KS, Wolf YI, Gootenberg JS, Semenova E, et al. Discovery and functional characterization of diverse class 2 CRISPR-Cas systems. Mol Cell. 2015. https://doi.org/10.1016/j.molcel.2015.10.008.

48. Gootenberg JS, Abudayyeh OO, Kellner MJ, Joung J, Collins JJ, Zhang F. Multiplexed and portable nucleic acid detection platform with Cas13, Cas12a and Csm6. Science. 2018. https://doi. org/10.1126/science.aaq0179.

49. Gootenberg JS, Abudayyeh OO, Lee JW, Essletzbichler P, Dy AJ, Joung J, et al. Nucleic acid detection with CRISPR-Cas13a/ C2c2. Science. 2017. https://doi.org/10.1126/science.aam9321.

50. Wang Y, Kang H, Liu X, Tong Z. Combination of RT-qPCR testing and clinical features for diagnosis of COVID-19 facilitates management of SARS-CoV-2 outbreak. J Med Virol. 2020c;92:538-9. https://doi.org/10.1002/jmv.25721.

51. Metsky HC, Freije CA, Kosoko-Thoroddsen T-SF, Sabeti PC, Myhrvold C. CRISPR-based surveillance for COVID-19 using genomically-comprehensive machine learning design. BioRxiv. 2020. https://doi.org/10.1101/2020.02.26.967026.

52. Zhang F, Abudayyeh OO, Gootenberg JS, Sciences C, Mathers L. A Protocol for Detection of COVID-19 using CRISPR Diagnostics v.20200321. 2020. (Sherlock Biosciences, Broad Institute, MIT: Cambridge).

53. Chen JS, Ma E, Harrington LB, Da Costa M, Tian X, Palefsky $\mathrm{JM}$, et al. CRISPR-Cas12a target binding unleashes indiscriminate single-stranded DNase activity. Science. 2018. https:// doi.org/10.1126/science.aar6245.

54. Freije CA, Myhrvold C, Boehm CK, Lin AE, Welch NL, Carter A, et al. Programmable inhibition and detection of RNA viruses using Cas13. Mol Cell. 2019;76:826-37.e11. https://doi.org/10. 1016/j.molcel.2019.09.013.

55. Abbott TR, Dhamdhere G, Liu Y, Lin X, Goudy LE, Zeng L, et al. Development of CRISPR as a prophylactic strategy to combat novel coronavirus and influenza. BioRxiv. 2020;1-20. https://doi.org/10.1101/2020.03.13.991307.

56. Yang LZ, Wang Y, Li SQ, Yao RW, Luan PF, Wu H, et al. Dynamic imaging of RNA in living cells by CRISPR-Cas 13 systems. Mol Cell. 2019. https://doi.org/10.1016/j.molcel.2019. 10.024 .

57. Carrat F, Flahault A. Influenza vaccine: the challenge of antigenic drift. Vaccine. 2007. https://doi.org/10.1016/j.vaccine. 2007.07.027.

58. Schubert S, Kurreck J. Oligonucleotide-based antiviral strategies. Handb Exp Pharmacol. 2006. https://doi.org/10.1007/3-54027262-3-13.

59. Sardone V, Zhou H, Muntoni F, Ferlini A, Falzarano MS. Antisense oligonucleotide-based therapy for neuromuscular disease. Molecules. 2017;22:563. https://doi.org/10.3390/molecules22040563.

60. Kimonis V, Weiss L, Carrer M, Yu H, Raben N, Grossman TR. Antisense oligonucleotide treatment targeting glycogen synthase (GYS1) in a mouse model of Pompe disease. Mol Gene Metab. 2019;126:S85.

61. Leavitt BR, Tabrizi SJ. Antisense oligonucleotides for neurodegeneration. Science. 2020;367:1428-9. https://doi.org/10. 1126/science.aba4624.

62. Moreno PMD, Pêgo AP. Therapeutic antisense oligonucleotides against cancer: hurdling to the clinic. Front Chem. 2014;2:87 https://doi.org/10.3389/fchem.2014.00087.

63. Muth CC. ASO therapy: hope for genetic neurological diseases. JAMA. 2018;319:644-6. https://doi.org/10.1001/jama.2017. 18665.

64. Scoles DR, Minikel EV, Pulst SM. Antisense oligonucleotides: a primer. Neurol Genet. 2019;5:e323. https://doi.org/10.1212/ NXG.0000000000000323.

65. van Roon-Mom WMC, Roos RAC, de Bot ST. Dose-dependent lowering of mutant huntingtin using antisense oligonucleotides in huntington disease patients. Nucleic Acid Therap. 2018;28:59-62. https://doi.org/10.1089/nat.2018.0720.

66. DeVos SL, Goncharoff DK, Chen G, Kebodeaux CS, Yamada K, Stewart FR, et al. Antisense reduction of tau in adult mice protects against seizures. J Neurosci. 2013;33:12887-97. https://doi. org/10.1523/JNEUROSCI.2107-13.2013.

67. Ly CV, Miller TM. Emerging antisense oligonucleotide and viral therapies for amyotrophic lateral sclerosis. Curr Opin Neurol. 2018;31:648-54. https://doi.org/10.1097/WCO.0000000000000594.

68. McCampbell A, Cole T, Wegener AJ, Tomassy GS, Setnicka A, Farley BJ, et al. Antisense oligonucleotides extend survival and reverse decrement in muscle response in ALS models. J Clin Investig. 2018;128:3558-67. https://doi.org/10. 1172/JCI99081.

69. Chery J, Petri A, Wagschal A, Lim SY, Cunningham J, Vasudevan S, et al. Development of locked nucleic acid antisense oligonucleotides targeting Ebola viral proteins and host factor Niemann-pick C1. Nucleic Acid Therap. 2018. https://doi.org/ 10.1089/nat.2018.0722.

70. De Jong YP, Jacobson IM. Antisense therapy for hepatitis C virus infection. J Hepatol. 2014. https://doi.org/10.1016/j.jhep. 2013.08.028.

71. Lenartowicz E, Nogales A, Kierzek E, Kierzek R, MartínezSobrido L, Turner DH. Antisense oligonucleotides targeting influenza A segment 8 genomic RNA inhibit viral replication. Nucleic Acid Therap. 2016. https://doi.org/10.1089/nat.2016. 0619.

72. Zhang Li, Li Q, Ding X, Zhang B, Zhang Q, Qu X, et al. Antisense oligonucleotides targeting Raf-1 block Japanese encephalitis virus in vitro and in vivo. Nucleic Acid Therap. 2017. https://doi.org/10.1089/nat.2016.0626.

73. Crooke ST, Ecker DJ, Sampath R, Freier SM, Massire C, Hofstadler SA, et al. Compositions and methods for the treatment of severe acute respiratory syndrome (SARS). 2004. WO2005023083A3.

74. Iversen PL. Sense Antiviral Compound And Method For Treating ssRNA Viral Infection. 2004. WO2005013905A2. 
75. Smith Alvin W, Iversen Patrick L, Stein David A, Skilling Douglas E. Antisense antiviral agent and method for treating ssRNA Viral Infection. 2004. https://www.surechembl.org/ document/CA-2522508-A1.

76. Barrey E, Burzio V, Dhorne-pollet S, Delmas B. Think different with RNA therapy: can antisense oligonucleotides be used to inhibit replication and transcription of SARS-Cov-2? Prepints.Org. 2020;1-23. https://doi.org/10.20944/preprints202004.0412.v1.

77. Neuman BW, Stein DA, Kroeker AD, Churchill MJ, Kim AM, Kuhn P, et al. Inhibition, escape, and attenuated growth of severe acute respiratory syndrome coronavirus treated with antisense morpholino oligomers. J Virol. 2005. https://doi.org/10.1128/jvi. 79.15.9665-9676.2005.

78. Pal M, Berhanu G, Desalegn C, Kandi V. Severe acute respiratory syndrome coronavirus-2 (SARS-CoV-2): an update. Cureus, 2. 2020. https://doi.org/10.7759/cureus.7423.

79. Rossi JJ, Rossi D. Oligonucleotides and the COVID-19 pandemic: a perspective. Nucleic Acid Therap. 2020. https://doi.org/ 10.1089/nat.2020.0868.

80. Mansoor M, Melendez AJ. Advances in antisense oligonucleotide development for target identification, validation, and as novel therapeutics. Gene Regul Systems Biol. 2008. https://doi. org/10.4137/grsb.s418.

81. Galderisi U, Cascino A, Giordano A. Antisense oligonucleotides as therapeutic agents. J Cell Physiol. 1999;181:251-7. https:// doi.org/10.1002/(SICI)1097-4652(199911)181:2<251::AIDJCP7>3.0.CO;2-D.

82. Nielsen PE, Egholm M, Berg RH, Buchardt O. Sequenceselective recognition of DNA by strand displacement with a thymine-substituted polyamide. Science. 1991. https://doi.org/ 10.1126/science. 1962210.

83. Shakeel S, Karim S, Ali A. Peptide nucleic acid (PNA)—a review. J Chem Technol Biotechnol. 2006. https://doi.org/10. 1002/jctb. 1505 .

84. Ghaffari E, Rezatofighi SE, Ardakani MR, Rastegarzadeh S. Delivery of antisense peptide nucleic acid by gold nanoparticles for the inhibition of virus replication. Nanomedicine. 2019. https://doi.org/10.2217/nnm-2018-0520.

85. Pellestor F, Paulasova P. The peptide nucleic acids (PNAs), powerful tools for molecular genetics and cytogenetics. Eur J Hum Genet. 2004. https://doi.org/10.1038/sj.ejhg. 5201226.

86. Nielsen PE. Peptide nucleic acid (PNA) from DNA recognition to antisense and DNA structure. Biophys Chem. 1997;68:103-8. https://doi.org/10.1016/s0301-4622(97)00019-7.

87. Su X, Kanjanawarut R. Control of metal nanoparticles aggregation and dispersion by PNA and PNA-DNA complexes, and its application for colorimetric DNA detection. ACS Nano. 2009. https://doi.org/10.1021/nn9005768.

88. Hanvey JC, Peffer NJ, Bisi JE, Thomson SA, Cadilla R, Josey JA, et al. Antisense and antigene properties of peptide nucleic acids. Science. 1992. https://doi.org/10.1126/science. 1279811.

89. Dean DA. Peptide nucleic acids: Versatile tools for gene therapy strategies. Adv Drug Deliv Rev. 2000. https://doi.org/10.1016/ S0169-409X(00)00087-9.

90. Koppelhus U, Zachar V, Nielsen PE, Liu X, Eugen-Olsen J, Ebbesen P. Efficient in vitro inhibition of HIV-1 gag reverse transcription by peptide nucleic acid (PNA) at minimal ratios of PNA/RNA. Nucleic Acids Res. 1997. https://doi.org/10.1093/na $\mathrm{r} / 25.11 .2167$.

91. Kaushik N, Basu A, Pandey VN. Inhibition of HIV-1 replication by anti-trans-activation responsive polyamide nucleotide analog. Antiviral Res. 2002;56:13-27.
92. Lee R, Kaushik N, Modak MJ, Vinayak R, Pandey VN. Polyamide nucleic acid targeted to the primer binding site of the HIV1 RNA genome blocks in Vitro HIV-1 reverse transcription. Biochemistry. 1998. https://doi.org/10.1021/bi972197m.

93. Tripathi S, Chaubey B, Barton BE, Pandey VN. Anti HIV-1 virucidal activity of polyamide nucleic acid-membrane transducing peptide conjugates targeted to primer binding site of HIV-1 genome. Virology. 2007;363:91-103. https://doi.org/10.1016/j. virol.2007.01.016.

94. Lu R, Zhao X, Li J, Niu P, Yang B, Wu H, et al. Genomic characterisation and epidemiology of 2019 novel coronavirus: implications for virus origins and receptor binding. Lancet. 2020. https://doi.org/10.1016/S0140-6736(20)30251-8.

95. Ahn D-G, Lee W, Choi J-K, Kim S-J, Plant EP, Almazán F, et al. Interference of ribosomal frameshifting by antisense peptide nucleic acids suppresses SARS coronavirus replication. Antivi Res. 2011. https://doi.org/10.1016/j.antiviral.2011.04.009.

96. Kruse RL. Therapeutic strategies in an outbreak scenario to treat the novel coronavirus originating in Wuhan, China. F1000Research. 2020. https://doi.org/10.12688/f1000research. 22211.1.

97. Elias Q, Raman B, Adele R, Saltzman WM, Glazer PM. Therapeutic peptide nucleic acids: principles, limitations, and opportunities. Yale J Biol Med. 2017;90:583-98. https:// pubmed.ncbi.nlm.nih.gov/29259523.

98. Wittung P, Kajanus J, Edwards K, Haaima G, Nielsen PE, Nordén B, et al. Phospholipid membrane permeability of peptide nucleic acid. FEBS Lett. 1995;375:27-9.

99. Youngren-Ortiz SR, Gandhi NS, España-Serrano L, Chougule MB. Aerosol delivery of siRNA to the lungs. part 1: rationale for gene delivery systems. KONA Powder Part J. 2016. https://doi. org/10.14356/kona.2016014.

100. Puerta-Fernández, E Romero-López C, Barroso-delJesus A, Berzal-Herranz A. Ribozymes: recent advances in the development of RNA tools. FEMS Microbiol Rev. 2003. https://doi.org/ 10.1016/S0168-6445(03)00020-2.

101. Stobart MJ, Simon SLR, Plews M, Lamoureux L, Knox JD. Efficient knockdown of human prnp mRNA expression levels using hybrid hammerhead ribozymes. J Toxicol Environ Health. 2009;72:1034-9. https://doi.org/10.1080/15287390903084314.

102. Feng Y, Leavitt M, Tritz R, Duarte E, Kang D, Mamounas M, et al. Inhibition of CCR5-dependent HIV-1 infection by hairpin ribozyme gene therapy against CC-chemokine receptor 5 . Virology. 2000;276:271-8. https://doi.org/10.1006/viro.2000.0536.

103. Lieber A, He CY, Polyak SJ, Gretch DR, Barr D, Kay MA. Elimination of hepatitis $\mathrm{C}$ virus RNA in infected human hepatocytes by adenovirus-mediated expression of ribozymes. J Virol. 1996;70:8782-91. https://doi.org/10.1128/JVI.70.12. 8782-8791.1996.

104. Mitsuyasu RT, Merigan TC, Carr A, Zack JA, Winters MA, Workman C, et al. Phase 2 gene therapy trial of an anti-HIV ribozyme in autologous $\mathrm{CD} 34+$ cells. Nat Med. 2009;15:285-92. https://doi.org/10.1038/nm.1932.

105. Nazari R, Ma XZ, Joshi S. Inhibition of human immunodeficiency virus- 1 entry using vectors expressing a multimeric hammerhead ribozyme targeting the CCR5 mRNA. J Gen Virol. 2008;89:2252-61. https://doi.org/10.1099/vir.0.2008/001222-0.

106. Tang XB, Hobom G, Luo D. Ribozyme mediated destruction of influenza $A$ virus in vitro and in vivo. $J$ Med Virol. 1994;42:385-95. https://doi.org/10.1002/jmv.1890420411.

107. Koseki S, Tanabe T, Tani K, Asano S, Shioda T, Nagai Y, et al. Factors governing the activity in vivo of ribozymes transcribed by RNA polymerase III. J Virol. 1999;73:1868-77. https://doi. org/10.1128/JVI.73.3.1868-1877.1999. 
108. Li W, Liu Y, Wang Y, Li R, Trang P, Tang W, et al. Engineered RNase $\mathrm{P}$ ribozymes effectively inhibit the infection of murine cytomegalovirus in animals. Theranostics. 2018;8:5634-44. https://doi.org/10.7150/thno.27776.

109. Trang P, Hsu A, Zhou T, Lee J, Kilani AF, Nepomuceno E, et al. Engineered RNase $\mathrm{P}$ ribozymes inhibit gene expression and growth of cytomegalovirus by increasing rate of cleavage and substrate binding. J Mol Biol. 2002;315:573-86. https://doi.org/ 10.1006/jmbi.2001.5291.

110. Fritz E, Wolfgang P, Fritz B, B OD, M WD, Olaf H. Modified ribozymes. 1993. https://www.surechembl.org/document/US5672695-A.

111. Dhama K, Khan S, Tiwari R, Sircar S, Bhat S, Malik YS, et al. Coronavirus disease 2019-COVID-19. Clin Microbiol Rev. 2020;33,e00028-20. https://doi.org/10.1128/CMR.00028-20.

112. Lee RTH, Ng ASM, Ingham PW. Ribozyme mediated gRNA Generation for in vitro and in vivo CRISPR/Cas9 mutagenesis. PLoS ONE. 2016. https://doi.org/10.1371/journal.pone.0166020.

113. Walker MP, Lindner SE. Ribozyme-mediated, multiplex CRISPR gene editing and CRISPR interference (CRISPRi) in rodent-infectious Plasmodium yoelii. J Biol Chem. 2019. https:// doi.org/10.1074/jbc.RA118.007121.

114. He Y, Zhang T, Yang N, Xu M, Yan L, Wang L, et al. Selfcleaving ribozymes enable the production of guide RNAs from unlimited choices of promoters for CRISPR/Cas9 mediated genome editing. J Genet Genom. 2017. https://doi.org/10.1016/j. jgg.2017.08.003.

115. Macpherson JL, Ely JA, Sun LQ, Symonds GP. Ribozymes in gene therapy of HIV-1. Front Biosci. 1999;4:D497-505. https:// doi.org/10.2741/macpherson.

116. Dash PK, Kaminski R, Bella R, Su H, Mathews S, Ahooyi TM, et al. Sequential LASER ART and CRISPR treatments eliminate HIV-1 in a subset of infected humanized mice. Nat Commun. 2019;10:2753. https://doi.org/10.1038/s41467-01910366-y.

117. Junker U, Baker J, Kalfoglou CS, Veres G, Kaneshima H, Böhnlein E. Antiviral potency of drug-gene therapy combinations against human immunodeficiency virus type 1. AIDS Res Human Retroviruses. 1997;13:1395-402. https://doi.org/10. 1089/aid.1997.13.1395

118. Valencia-Reséndiz DG, Palomino-Vizcaino G, Tapia-Vieyra JV, Benítez-Hess ML, Leija-Montoya AG, Alvarez-Salas LM. Inhibition of human papillomavirus Type 16 infection using an RNA aptamer. Nucleic Acid Therap. 2018. https://doi.org/10.1089/nat. 2017.0687.

119. Yu X, Gao Y, Xue B, Wang X, Yang D, Qin Y, et al. Inhibition of hepatitis $\mathrm{C}$ virus infection by NS5A-specific aptamer. Antivir Res. 2014. https://doi.org/10.1016/j.antiviral.2014.03.020.

120. Kwon HM, Lee KH, Han BW, Han MR, Kim DH, Kim DE. An RNA aptamer that specifically binds to the glycosylated hemagglutinin of avian influenza virus and suppresses viral infection in cells. PLoS ONE. 2014. https://doi.org/10.1371/ journal.pone.0097574.

121. Hirao I, Kimoto M, Lee KH. DNA aptamer generation by ExSELEX using genetic alphabet expansion with a mini-hairpin DNA stabilization method. Biochimie. 2018;145:15-21. https:// doi.org/10.1016/j.biochi.2017.09.007.

122. Kimoto M, Nakamura M, Hirao I. Post-ExSELEX stabilization of an unnatural-base DNA aptamer targeting VEGF165 toward pharmaceutical applications. Nucleic Acids Res. 2016;44:7487-94. https://doi.org/10.1093/nar/gkw619.

123. Tang W, Hu JH, Liu DR. Aptazyme-embedded guide RNAs enable ligand-responsive genome editing and transcriptional activation. Nat Commun. 2017. https://doi.org/10.1038/ncomms15939.
124. Zhou J, Lazar D, Li H, Xia X, Satheesan S, Charlins P, et al. Receptor-targeted aptamer-siRNA conjugate-directed transcriptional regulation of HIV-1. Theranostics. 2018. https://doi.org/ 10.7150/thno.23085.

125. Liu C, Zhou Q, Li Y, Garner LV, Watkins SP, Carter LJ, et al. Research and development on therapeutic agents and vaccines for COVID-19 and related human coronavirus diseases. ACS Cent Sci. 2020. https://doi.org/10.1021/acscentsci.0c00272.

126. Kang J, Yeom G, Ha SJ, Kim MG. Development of a DNA aptamer selection method based on the heterogeneous sandwich form and its application in a colorimetric assay for influenza A virus detection. N. J Chem. 2019. https://doi.org/10.1039/ c8nj06458j.

127. Lee KH, Zeng H. Aptamer-based ELISA assay for highly specific and sensitive detection of Zika NS1 protein. Anal Chem. 2017. https://doi.org/10.1021/acs.analchem.7b02862.

128. Liebich S. COVID-19 Potential treatment/prophylaxis method research proposal solubilized oligonucleotide ssDNA aptamers designed against the RBD motif of Spike protein delivered in dose-dependent manner through inhalation. 2020. https://doi.org/ 10.13140/RG.2.2.15454.18242.

129. Ahn DG, Jeon IJ, Kim JD, Song MS, Han SR, Lee SW, et al. RNA aptamer-based sensitive detection of SARS coronavirus nucleocapsid protein. Analyst. 2009. https://doi.org/10.1039/ b906788d.

130. Jang KJ, Lee NR, Yeo WS, Jeong YJ, Kim DE. Isolation of inhibitory RNA aptamers against severe acute respiratory syndrome (SARS) coronavirus NTPase/Helicase. Biochem Biophys Res Commun. 2008. https://doi.org/10.1016/j.bbrc.2007.12.020.

131. Carthew RW, Sontheimer EJ. Origins and Mechanisms of miRNAs and siRNAs. Cell. 2009. https://doi.org/10.1016/j.cell. 2009.01.035.

132. Kim DH, Rossi JJ. RNAi mechanisms and applications. BioTechniques. 2008. https://doi.org/10.2144/000112792.

133. Wang S, Zhang Y, Liu S, Peng H, Mackey V, Sun L. Coronaviruses and the associated potential therapeutics for the viral infections. J Infect Dis Ther. 2020b;8:1-8.

134. Shi Y, Yang DH, Xiong J, Jia J, Huang B, Jin YX. Inhibition of genes expression of SARS coronavirus by synthetic small interfering RNAs. Cell Res. 2005. https://doi.org/10.1038/sj.cr. 7290286.

135. Li T, Zhang Y, Fu L, Yu C, Li X, Li Y, et al. siRNA targeting the Leader sequence of SARS-CoV inhibits virus replication. Gene Ther. 2005. https://doi.org/10.1038/sj.gt.3302479.

136. Chen W, Feng P, Liu K, Wu M, Lin H. Computational identification of small interfering RNA targets in SARS-CoV-2. Virol Sinica. 2020b. https://doi.org/10.1007/s12250-020-00221-6.

137. Kumar V, Jung YS, Liang PH. Anti-SARS coronavirus agents: a patent review (2008-present). Expert Opin Therap Patents. 2013. https://doi.org/10.1517/13543776.2013.823159.

138. Liang Q, Li J, Guo M, Tian X, Liu C, Wang X, et al. Virus-host interactome and proteomic survey of PMBCs from COVID-19 patients reveal potential virulence factors influencing SARSCoV-2 pathogenesis. BioRxiv. 2020. https://doi.org/10.1101/ 2020.03.31.019216.

139. Wang Y, Cao YL, Yang F, Zhang Y, Wang SH, Liu L. Small interfering RNA effectively inhibits the expression of SARS coronavirus membrane gene at two novel targeting sites. Molecules. 2010. https://doi.org/10.3390/molecules15107197.

140. Merril J. Proposal for supportive/preventive treatment of COVID19 using siRNA to suppress expression of ACE2 receptors and vaccines based phage-display technology developed by epitopeRX. 2020;1-8. https://bitlattice.org/resources/ treatment-proposal-covid19.pdf. 
141. Lu CY, Huang HY, Yang TH, Chang LY, Lee CY, Huang LM. siRNA silencing of angiotensin-converting enzyme 2 reduced severe acute respiratory syndrome-associated coronavirus replications in Vero E6 cells. Eur J Clin Microbiol Infect Dis. 2008. https://doi.org/10.1007/s10096-008-0495-5.

142. Coleman CM, Sisk JM, Mingo RM, Nelson EA, White JM, Frieman MB. Abelson kinase inhibitors are potent inhibitors of severe acute respiratory syndrome coronavirus and middle east respiratory syndrome coronavirus fusion. J Virol. 2016. https:// doi.org/10.1128/jvi.01429-16.

143. Li X, Geng M, Peng Y, Meng L, Lu S. Molecular immune pathogenesis and diagnosis of COVID-19. J Pharm Anal. 2020b. https://doi.org/10.1016/j.jpha.2020.03.001.

144. Saw PE, Song EW. siRNA therapeutics: a clinical reality. Sci China Life Sci. 2019. https://doi.org/10.1007/s11427-0189438-y. 